\title{
XXXIII. On some formulæ which serve to indicate the limits of the application of indeterminate methods to the solution of certain problems
}

James Cockle M.A.

To cite this article: James Cockle M.A. (1846) XXXIII. On some formulæ which serve to indicate the limits of the application of indeterminate methods to the solution of certain problems, Philosophical Magazine Series 3, 29:193, 181-183, DOI: 10.1080/14786444608645611

To link to this article: http://dx.doi.org/10.1080/14786444608645611

曲 Published online: 30 Apr 2009.

Submit your article to this journal $[\pi$

Џll Article views: 2

Q View related articles $\sqsubset$ 
ment of the operation the dense fluid must have passed with the same velocity through the membrane as the rare one, which is contrary to the second fact. Therefore, in case of diffusion of two fluids of unequal densities through a porous partition, the fluid MUST accumulate on that side of the partition on which is situated that fluid which passed through it most slowly.

This explanation is applicable in all cases in which the rarer fluid on the one side of the membrane has the same chemical properties as that on the other side, their difference being only in their degree of density.

If these fluids be dissimilar in respect to their chenical qualities, still the accumulation will take place on that side of the menbrane on which was situated the fluid which passed through it most slowly, although its density may be less than the other; thus, for instance, when a bladder full of air is surrounded with carbonic acid, the latter enters faster than the former escapes, and the bladder bursts. Now it is found by experiment, that carbonic acid passes through wet membrane quicker than atmospheric air, although of a greater density.

In such instances the relative velocities of the passage of different fluids through membrane will be influenced by their chemical attraction for the material of which the membrane is composed, as well as by that attraction which is regulated by quantity of matter; and in some cases the existence of the latter force may be so modified by the former as to be wholly inappreciable; but still that force, being an universal agent, and acting upon all matter according to invariable laws, is in operation in every instance where the conditions requisite for endosmose and exosmose are present, although in some cases chemical attraction or electricity may have no demonstrable existence; and therefore it may be looked upon as the essential cause of endosmose and exosmose, chemical affinity, electricity, \&c. being merely the modifiers of its operation, and in respect to it, secondary agents.

XXXIII. On some Formulce which serve to indicate the limits of the application of Indeterminate Methods to the solution of certain Problems. By J 1 Mes CockLe, M.A., of Trinity College, Cambridge*.

THE equations distinguished below by unaccented numbers will respectively be found at p. 344, or one of the four succeeding pages, of the Report of the Sixth Meeting of

* Communicated by Sir George Cayley, Bart. 


\section{Mr. J. Cockle on the Solution of certain Problems.}

the British Association for the Advancement of Science, to which, for the purpose of avoiding prolixity, the author begs leave to refer the reader of this paper. It will be seen that, using the notation there einployed,

since

$$
\begin{aligned}
m(0,1,1) & =1+m(1,1)=4, . \\
m(0,0,1,1) & =1+m(1,1,1)=6, .
\end{aligned} .
$$

since

$$
\begin{array}{r}
m(0,0,0,1,1)=1+m(1,1,1,1)=12, . \\
m(1,1,1,1)=11 ; . \quad . \quad . \quad .
\end{array}
$$

10 may however be written for 11 in this last equation, for reasons which will be manifest on referring to page 34.8 of the above-mentioned Report; so that we may make

So $\quad m(0,0,0,0,1,1)=1+m(1,1,1,1,1)=48, . \quad\left(340^{\prime}\right.$.)

for

$$
m(0,0,0,1,1)=11 \text {. . . . . }\left(339^{\prime} .\right)
$$

and

$$
\begin{aligned}
& m(0,0,0,0,0,1,1)=1+m(1,1,1,1,1,1)=924, \\
& \text { since } m(1,1,1,1,1,1)=923 . \text {. . . }
\end{aligned}
$$

Now each of the newly-valued functions may for convenience be represented by $m\left(0^{r-1}, 1^{2}\right),-$ a very obvious abbreviation. Let $n\left(0^{r-1}, 1^{2}\right)$ denote the corresponding function when, instead of the process to which the above equations refer, we apply that which the writer of this paper has used in the last two volumes of the present series of this Magazine. Then, by investigations similar to those pursued in the particular cases already therein treated, he has been conducted to the general condition,

$$
n\left(0^{r-1}, 1^{2}\right)=2 r
$$

This last condition, which the author hopes to discuss on some future occasion, gives

$$
\begin{aligned}
& n(0,1,1)=4, \quad \text {. . . . . }\left(336^{\prime \prime} .\right) \\
& n(0,0,1,1)=6 \text {, . . . . . }\left(337^{\prime \prime} .\right) \\
& n(0,0,0,1,1)=8, \quad \cdot \quad\left(338^{\prime \prime} .\right) \text { or }\left(339^{\prime \prime} .\right) \\
& n(0,0,0,0,1,1)=10, \text {. . . . }\left(340^{\prime \prime} .\right) \\
& n(0,0,0,0,0,1,1)=12 \text {. . . . }\left(341^{\prime \prime} .\right)
\end{aligned}
$$

On the condition marked $\left(338^{\prime \prime}\right.$.) or $\left(339^{\prime \prime}\right.$.) is founded a proposition announced at p. 405 of the last $(4.4 \mathrm{th})$ volume of the Mechanics' Magazine. The more general one, which will be found at p. 36 of No. 1196 of that work, is based upon the above condition $\left({ }^{\prime \prime}\right.$.)

Of course the consicleration of the above propositions will require some extensions of the formula given by the writer 
at p. 396 of the last volume of the Philosophical Magazine. We shall have, for instance, to reduce $f^{5}\left(w_{m}\right)$ to the form $\Sigma_{m}\left(h^{5}\right)$. To determine $w_{m}$ we must employ a new equation of finite differences, viz.

$$
w_{x+1}-3.2^{2 u_{2 w_{x}}+1}+2=0
$$

when $w_{0}=1$ and $u$ has the same meaning as at the page last cited. Were it desirable, it would not be difficult to generalize this equation of differences so as to obtain the corresponding one for functions of any degree.

Grecian Chambers, Devereux Court, July $20,1846$.

XXXIV. Facts and Observations relating to the Science of Phonetics (No. IV.). By R. G. LathaM, M.D., Cant.*

T $\mathrm{N}$ a previous Number it was stated that the mutes $s$ and $z$ 1 had certain peculiarities. In explaining the nature of these it is necessary to enter into some points of classification and nomenclature.

The sounds $p, b, t, d, k, g, s, z$ are called lene sounds (or Lenes), as opposed to $f, v, \gamma, \gamma, x, \gamma, \sigma, \zeta$, which are called aspirate sounds (or Aspirates). This division is as old as the time of the classical grammarians, and is generally recognised. Hence the division, -

$$
\begin{array}{lll}
\multicolumn{2}{c}{\text { Lene. }} \\
p & \cdot & b \\
t & \cdot & d \\
k & \cdot & g \\
s & \cdot & z
\end{array}
$$$$
\begin{array}{cc}
\text { Aspirate. } \\
f & v \\
p & \gamma \\
x & \gamma \\
\sigma & \zeta
\end{array}
$$

By the side of this should be placed the division of sounds into what is called explosive and continuous. If we isolate the sound of $p$ ' as much as possible, so as to join with it no vowel whatsoever, we find that the articulation is only of a momentary duration, "taking place during a sudden change in the conformation of the mouth, and not capable of prolongation." (Müller's Physiology, Baly's translation, p. 1045.) The same is the case with the sounds of $b, t, d, k, g$.

In contrast to this we may isolate such a sound as $f$ '. Here the sound can be "prolonged, ad libitum, as long as a particular disposition of the mouth and a constant expiration nre maintained" (Ibid.).

It is upon these differences that the names explosive (strepitus incontinuus explosivus) and continuous (strepitus continuus) are given by even the earlier writers upon these subjects; and, * Communicated by the Author. 